\title{
Mesothelioma in Australia: cresting the
}

\section{third wave}

\section{Bruce Armstrong a and Tim Driscolla,b}

a School of Public Health, University of Sydney, NSW, Australia

bCorresponding author: tim.driscoll@sydney.edu.au

\section{Article history}

\section{Publication date: April 2016}

Citation: Armstrong B, Driscoll T. Mesothelioma in Australia: cresting the third wave. Public Health Res Pract. 2016;26(2):e2621614. doi: http://dx.doi. org/10.17061/phrp2621614

\section{Key points}

- The timing and extent of the third wave of asbestos-related illness are not known

- Information is needed on exposures arising from a range of third-wave tasks and in situ asbestos

- Exposure information should be used to inform evidence based actions to eliminate or minimise exposures

\section{Abstract}

There has been much recent commentary about the 'third wave' of asbestosrelated disease, arising particularly from exposures of people repairing, renovating or demolishing buildings that contain asbestos. The presence and extent of a third wave, however, are difficult to assess, and the extent and risk of both occupational and nonoccupational third-wave exposures are largely unmeasured. Moreover, we lack information on the extent of deterioration of in situ asbestos, and its significance for ambient and third-wave exposures. This paper considers the available evidence about the third wave. It proposes approaches to obtaining the information needed to properly estimate the risk of third-wave exposures, and guide actions that will crest a likely third wave with minimum harm and cost to the community.

\section{Introduction}

The Chairman of the Australian Government's Asbestos Management Review, which reported in June 2012, wrote in the review report's introduction:1

Of particular concern are recent studies that indicate the incidence of mesothelioma is increasing. Asbestos-related diseases have traditionally been linked to workers who have had direct contact with the material, either through mining or working with asbestos in manufacturing processes. A developing demographic whom asbestosrelated diseases affect is appearing in the population, and includes 'do-it-yourself' (D/Y) home renovators and their families. In the absence of timely and decisive intervention, many more people for generations to come will continue to contract these avoidable incurable fatal illnesses.

This would be the third phase of asbestos-related disease that Philip Landrigan postulated in $1991^{2}$, which is often referred to as the 'third wave': asbestos-related disease in people repairing, renovating or demolishing asbestos-containing buildings. The first wave was due to mining and milling ore, and making asbestos products, and the second wave was due to working with and using the products. Landrigan probably coined the term 'third wave' in relation to occupational exposure, although there is some 
ambiguity in this regard. For the purposes of this paper, we define third-wave exposure as both occupational and nonoccupational exposure to asbestos as a consequence of repair, renovation and demolition of buildings, and environmental exposure to asbestos (excluding ambient exposure and exposure to asbestos from natural resources).

There has been much recent commentary about thirdwave exposures. ${ }^{1,3-8}$ Is a third wave likely or is it already upon us? Trends in the rates of malignant mesothelioma - the sentinel disease for asbestos exposure - may inform us. Knowledge of levels of, and trends in, exposure to asbestos during repair, renovation and demolition is essential to gain a proper understanding of the risks. Also essential is knowledge of the extent of deterioration of in situ asbestos and its significance for exposure.

\section{Is Australia's incidence of mesothelioma rising?}

Australia's cancer registries indicate that the incidence of mesothelioma is not rising. The most recent data (Figure 1) suggest that, after rising for at least 20 years, the age-standardised incidence of mesothelioma plateaued in 2002 for women and in 2004 for men. ${ }^{9}$ These are the most reliable data we have to assess mesothelioma trends. They do not exclude the possibility that an emerging third wave is masked by the progressive exhaustion of effects of the first and second waves.

\section{Are third-wave exposures common in people diagnosed with mesothelioma?}

Data collected for the Australian Mesothelioma Registry, although based on only about $15 \%$ of newly diagnosed mesotheliomas, suggest that third-wave exposures may now be important. ${ }^{10}$ Of 449 people newly diagnosed with mesothelioma between 1 July 2010 and 1 April 2015 who gave information, 101 (22\%) had worked in construction - which includes repair, renovation and demolition of buildings (but also second-wave use of asbestos products) - and $88 \%$ were judged to have had probable high exposure to asbestos. With respect to third-wave nonoccupational exposure, 57\% of the 449 had done (unpaid) major home renovations involving asbestos products ( $8 \%$ of the 449 were judged to have had probable exposure), and $43 \%$ had lived in a house during major renovations (none with probable exposure). These figures suggest, but do not establish, that home renovation is now contributing to mesothelioma risk in Australia. However, the extent to which the $15 \%$ of all people with newly diagnosed mesothelioma who gave information to the Registry were representative of all such people is not clear, and bias in the choice to participate is likely.

In a 2008 mail survey of 10000 adults listed on the New South Wales (NSW) Electoral Roll, 37.5\% of whom gave information, $24 \%$ reported having done DIY (do

Figure 1 Trends in age-standardised incidence of mesothelioma in Australian males and females, 1982-2011³
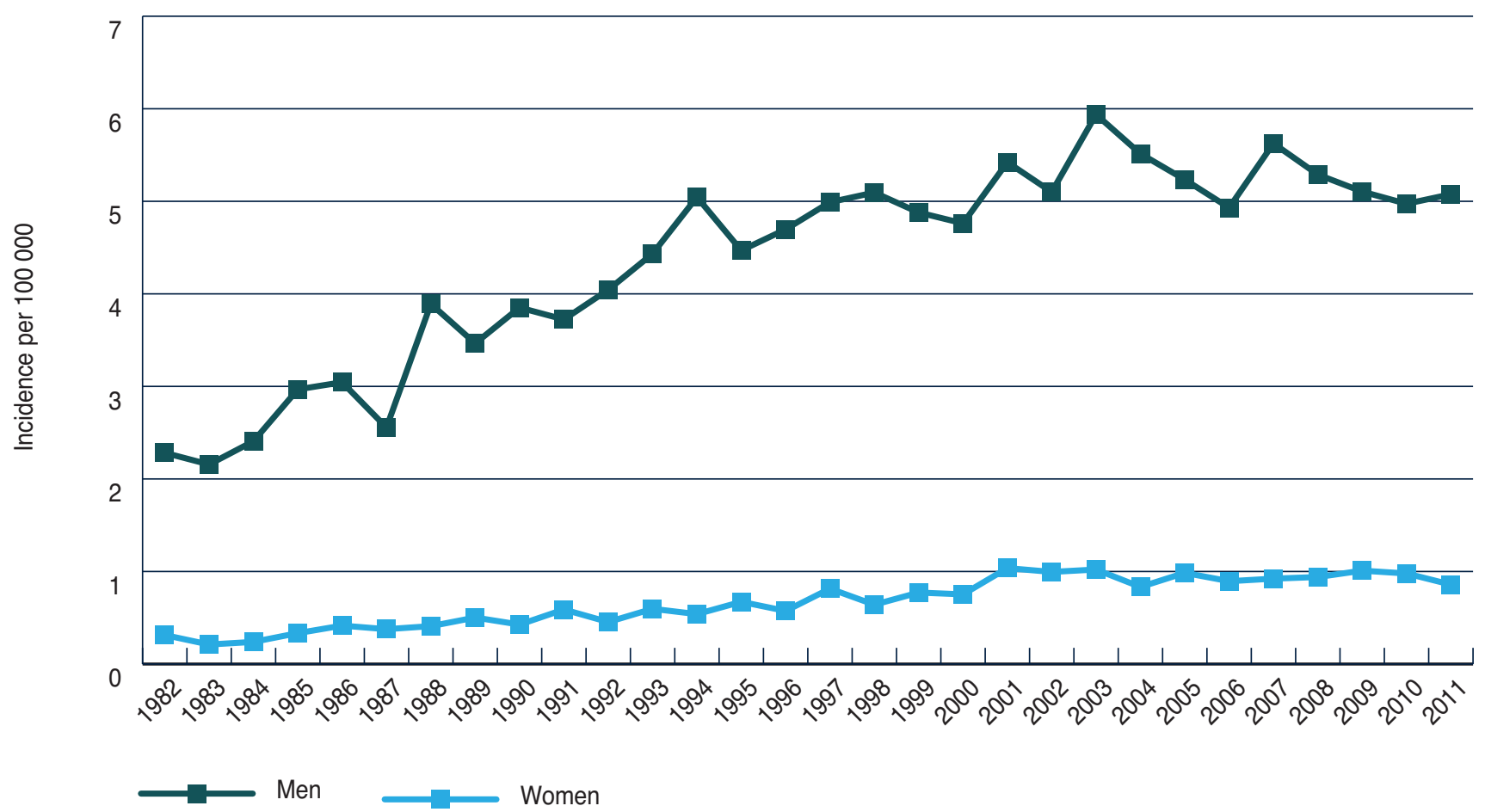
it yourself) home renovations. Of these, $61 \%$ reported asbestos exposure during the renovation, ranging from contact with asbestos cement sheeting ( $96 \%$ of those reporting asbestos exposure) to contact with asbestos insulation (14\%; loose-fill asbestos insulation, mainly amosite, was used in some Australian houses $\left.{ }^{11}\right)$ and cutting (54\%), drilling (41\%) or sanding (19\%) asbestos building materials. A total of $20 \%$ of participants reported other home renovations, of whom only $3 \%$ reported asbestos exposure. ${ }^{6}$

The proportions of all survey participants who reported cutting (8\%), drilling (6\%) or sanding (3\%) asbestos materials as DIY renovators are similar to the proportion of mesothelioma patients providing information to the Australian Mesothelioma Registry who were judged to have probable asbestos exposure from unpaid home renovation (8\%). Thus, on this limited assessment, DIY renovators do not appear to be overrepresented in present Registry data.

An analysis of trends in the reported sources of asbestos exposure of people registered as diagnosed with mesothelioma in Western Australia (WA) between 1960 and 2008 reached an apparently different conclusion: "Our study confirms the rising trend in diagnosis of malignant mesothelioma resulting from exposure to asbestos during renovation activities in and around the home". ${ }^{5}$ However, in reaching its conclusion about causes, this report could not take account of any time trend in home renovation activity, particularly of houses partly constructed from asbestos in the 1950s to 1980s. We have estimated from a graphical presentation of the authors' data (Box 2 in their paper) that the most significant source of exposure of mesothelioma patients in WA was "handyman, home maintenance and DIY" in $2 \%$ of patients with exposure information in 1995-99, 7\% in 2000-04 and 15\% in 2005-08. (All mesothelioma patients whose most significant source of exposure was other than as a worker or resident in Wittenoom, a former asbestos mining town in WA, were used as the denominator for these estimates to correct for the otherwise higher base rates of mesothelioma in WA than in the rest of Australia.) Although $15 \%$ is appreciably above the $8 \%$ from the Australian Mesothelioma Registry, it could easily be close to the proportion of the NSW survey participants who were DIY home renovators and did any cutting, drilling or sanding of asbestos materials. Moreover, the WA exposure definition "handyman, home maintenance and DIY" encompasses more than simply DIY home renovation. Substantial changes over time in the way exposure data used in the study have been collected in WA may also have influenced the observed trends. ${ }^{5}$ Therefore, the WA data give no stronger indication than the national data of a possible contribution of nonoccupational exposure to a third wave of asbestosrelated disease.
What do we know of the levels of third-wave exposures and their potential to increase asbestosrelated disease?

Measurements of exposure to asbestos required and collected by the NSW Dust Diseases Board provide evidence of modest but uncertain increase in fibre concentrations in the breathing zone of workers handling asbestos cement products in the 1980s, with a mean concentration of 0.8 fibres per millilitre $(\mathrm{f} / \mathrm{mL})(95 \%$ confidence interval $[95 \% \mathrm{Cl}] 0.01,2.1)$ from 25 observations. ${ }^{12}$ The circumstances of these observations (e.g. as second-wave or third-wave exposures) are not specified. The exposures were higher for cutting $(1.5 \mathrm{f} / \mathrm{mL}$; $95 \% \mathrm{Cl} 0.1,3.6)$, drilling $(1.3 \mathrm{f} / \mathrm{mL}$; $95 \% \mathrm{Cl} 0.2,5.4)$, grinding ( $1.0 \mathrm{f} / \mathrm{mL} ; 95 \% \mathrm{Cl} 0.1,3.0)$ and sanding $(2.4 \mathrm{f} / \mathrm{mL} ; 95 \% \mathrm{Cl} 0.1,7.0)$ asbestos cement. Although it is probable that more recent exposure levels are lower, there is no organised and ongoing program of measurement and reporting of the asbestos exposure of construction industry workers against which to test this assumption.

We know of no other published study of the levels of asbestos exposure - occupational or nonoccupational - of people engaged in renovation of homes known to contain asbestos products. There has been one systematic review and meta-analysis of studies of mesothelioma incidence in relation to nonoccupational exposure of any kind. ${ }^{13}$ Although the pooled relative risk (RR) was quite high for household exposure (RR 8.1; $95 \% \mathrm{Cl} 5.3,12)$, the exposures were exclusively to family members who worked with asbestos. One of two later studies observed an odds ratio of $0.7(95 \% \mathrm{Cl} 0.4,1.2)$ for any type of DIY activity and no increase in risk with any type of asbestos in the house. ${ }^{14}$ The other did not analyse domestic DIY exposures separately from exposure for family members who worked with asbestos, or from living near industrial sources of asbestos. ${ }^{4}$

In the absence of human use of asbestos (e.g. in mining, milling, manufacturing and construction), ambient levels of asbestos are very low - around $0.00001 \mathrm{f} / \mathrm{mL}$ in rural and $0.0001 \mathrm{f} / \mathrm{mL}$ in urban outdoor air. ${ }^{15}$ These ambient levels possibly contribute to the background incidence of mesothelioma, estimated in the Danish population as 0.3 per 100000 population per year before the rise in pleural mesothelioma incidence began in men in $1953 .{ }^{16}$ In a compilation of quality measurements of asbestos concentrations in 1377 samples of air from 198 buildings constructed in part from asbestoscontaining materials, mean concentrations in the buildings varied from 0.0004 to $0.0024 \mathrm{f} / \mathrm{mL}$; for all data together, the mean was $0.0003 \mathrm{f} / \mathrm{mL}$ (90th centile 0.0007 , 95th centile 0.0014). ${ }^{15}$ Various scenarios of exposure to these levels gave estimated increases in lifetime risks of death from mesothelioma or lung cancer of 4 to 60 per 
million exposed people, although some have argued that these risks underestimate the true risk at very low levels of exposure. ${ }^{17}$ To give these risks some context, the current total lifetime risk of death from cancer in Australia is about 1 in 5 - that is, 200000 per million. ${ }^{18}$

Monitoring of air at nine sites close to deteriorating asbestos cement sheeting on school buildings in WA for a combined total of more than 720 hours detected one asbestos fibre at each of two schools and an estimated concentration of $0.0002 \mathrm{f} / \mathrm{mL}$ (upper $95 \%$ confidence bound $0.002 \mathrm{f} / \mathrm{mL}$ ). Similar monitoring elsewhere was reported to have observed concentrations of up to $0.0012 \mathrm{f} / \mathrm{mL} .^{19}$

\section{Cresting the third wave?}

Although the above observations are reassuring, they do not support complacency with respect to third-wave occupational exposures. As well, little is yet known of the potential impact of third-wave nonoccupational exposures. Elimination of asbestos from the built environment seems, on face value, to be a sensible idea. Asbestos exposure issues raised by rollout of the National Broadband Network in Australia illustrate the problem of leaving asbestos-containing material in situ if appropriate care is not taken when the material is disturbed. Public concern about asbestos, if nothing else, requires that these issues be addressed.

The wholesale removal of asbestos would carry a risk of unnecessary exposure, and would be an enormous and expensive undertaking. A targeted removal program based on sound estimates of the risk of removal and of nonremoval is necessary if the maximum amount of asbestos is to be removed with the lowest possible risk to workers and the community. At present, sound estimates of risk cannot be made because the likely exposure to asbestos that removal would entail has not been adequately characterised.

Less extremely, but still with major implications for many Australians, the 2012 report of the Asbestos Management Review proposed: ${ }^{1}$

\section{a requirement that an asbestos content report be undertaken by a competent assessor to determine and disclose the existence of ACMs [asbestos- containing materials] in residential properties constructed prior to 1987 at the point of sale or lease, and prior to renovation, together with a property labelling system to alert workers and potential purchasers and tenants to the presence of asbestos.}

It is very possible that this requirement will be introduced. Given the experience of asbestoscontaminated houses in the Australian Capital Territory ${ }^{11}$, where houses in which loose-fill asbestos was installed in the late 1960s and the 1970s are now being demolished because of community concern, this measure would cause substantial anxiety to affected residents and concern to affected owners, probably justified, about reduction in the value of their properties. It should not be introduced without rigorous assessment of its costs and benefits. Benefits cannot be fully assessed at present because we lack the estimates of asbestos exposure required to support rigorous estimation of the asbestosrelated disease the measure would prevent, either in residents or in tradespeople who might be exposed inadvertently while undertaking work on such houses.

To address these knowledge gaps, Australia needs accurate and ongoing monitoring of asbestos fibre concentrations in urban air, and the capacity to intensively measure fibre concentrations in proximity to areas and circumstances thought to present a particular hazard (e.g. renovation or demolition of homes constructed with asbestos cement products). Only with such careful and consistent measurement, and associated analysis will we know what the real risks are and what control measures are needed. Key questions needing answers are listed in Box 1. In addition, the available evidence based advice on the management of asbestos in Australian houses ${ }^{3}$ should be more widely disseminated.

Box 1 Examples of important research questions relating to third-wave asbestos exposure

- Ambient exposure

- What should be the reference level of ambient asbestos exposure in urban air for comparison with other exposure circumstances?

- DIY

- What are typical asbestos exposures from DIY home repair or renovation tasks to the person doing the work and those living in, or near, the repair or renovation?

- Asbestos in situ

- What are typical asbestos exposures from living in, or using, standard structures with asbestos in situ?

- What additional asbestos exposures arise from deterioration of asbestos-containing materials in standard structures with asbestos in situ?

- What asbestos exposures, to both the removalist and bystanders, arise during removal of asbestos in situ from standard structures?

- Exposures arising in disasters

- What asbestos exposures arise during and after natural and other disasters, such as bushfires, storms, earthquakes and structural fires?

- Asbestos in soil

What asbestos exposures arise from asbestoscontaining materials in soil, and in what circumstances do they arise? 
The Australian Government's Asbestos Safety and Eradication Agency (ASEA) and the Australian Mesothelioma Registry have particularly important roles to play in supporting a rational and evidence based approach to the third wave of asbestos exposure.

Established in July 2013, ASEA "provide[s] a national focus on asbestos issues which goes beyond workplace safety to encompass environmental and public health concerns" (www.asbestossafety.gov.au). One of its five key operating principles is that "decision making regarding asbestos management and awareness should be based on sound evidence and analysis from scientifically robust sources". It also has the power to "commission, monitor and promote research into the prevention of asbestos exposure and asbestos-related disease", which includes "commissioned research [that] identifies practical and innovative approaches to prevent or minimise risks from exposure to asbestos fibres". Its recently developed research plan has three key areas of focus: the current and future risks posed by asbestos in Australia, identification and elimination of risks posed by asbestos, and the economic and social impact of asbestos in Australia. One of its currently funded projects is 'Evidence based assessment of current risks from asbestos exposure'. ${ }^{7}$ An increase in ASEA's research funding would help supply the information needed for evidence based policy in this area. The research will require careful oversight to ensure that it directly addresses the policy needs.

Re-established in 2010, the Australian Mesothelioma Registry receives almost complete notification of incident cases of mesothelioma. The primary value of the Registry lies in the information it could provide on exposure, as referred to above. Critically, the present low proportion of patients newly diagnosed with mesothelioma for whom it obtains exposure information must be increased. Although difficult, this may be achievable by faster notification of, and consent from, patients, obtained through more active engagement of medical and nursing staff, mesothelioma support groups and legal representatives. The Registry should continue and, if necessary, be further enabled to take such steps. Otherwise, it will fail to achieve its most important goal.

\section{Conclusions}

The legacy of the mining of asbestos, and the manufacture and use of asbestos products, has seen Australians pay a heavy price - in terms of death and disability - from the first two waves of asbestos exposure and resulting disease. Currently, scientific evidence for the existence of the hypothesised third wave is limited. However, a third wave is likely to contribute to asbestosrelated disease in Australia in the future. Rigorously assessing evidence for the existence, height and power of this wave, and cresting it with minimum harm and cost to the community, require detailed information on relevant exposures and carefully considered, evidence based actions to prevent or minimise exposure.

\section{Competing interests}

TD is a member of the ASEA Research Advisory Committee and the Management Committee of the Australian Mesothelioma Registry. BA was a member of the Management Committee of the Australian Mesothelioma Registry until 2013.

\section{Author contributions}

BA conceived the idea for the paper. Both authors discussed the scope and content, wrote content, revised the original submission and approved the final version. 


\section{References}

1 Asbestos Management Review. Asbestos Management Review report - June 2012. Canberra: Australian Government Department of Employment; 2012 [cited 2016 Feb 25]. Available from: docs.employment.gov.au/ system/files/doc/other/asbestos_management_review_ report_june_2012.pdf

2 Landrigan PJ. The third wave of asbestos disease: exposure to asbestos in place. Public health control. Introduction. Ann N Y Acad Sci. 1991;643:xv-xvi.

3 Environmental Health Standing Committee (enHealth). Asbestos: a guide for householders and the general public. Canberra: Commonwealth of Australia; 2013 [cited 2016 Feb 25]. Available from: www.health.gov. au/internet/main/publishing.nsf/Content/ohp-enhealthasbestos-may2012.htm/\$File/asbestos-feb 13.pdf

4 Lacourt A, Gramond C, Rolland P, Ducamp A, Audignon S, Astoul P, et al. Occupational and nonoccupational attributable risk of asbestos exposure for malignant pleural mesothelioma. Thorax. 2014;69(6):532-9.

5 Olsen N, Franklin P, Reid A, de Klerk NH, Threllfall TJ, Shilkin K, Musk B. Increasing incidence of malignant mesothelioma after exposure to asbestos during home maintenance and renovation. Med J Aust. 2011;195:271-4.

6 Park E, Yates D, Hyland RA, Johnson AR. Asbestos exposure during home renovation in New South Wales. Med J Aust. 2013;199(6):410-13.

7 Reid A. Where are the current and future asbestos exposure risks in Australia? International conference on asbestos awareness and management; 2015 Nov 22-24; Brisbane. Brisbane: Asbestos Safety and Eradication Agency; 2015 [cited 2016 Feb 25]. Available from: www. asbestossafety.gov.au/sites/asbestos/files/ICAAM_2015_ Geza_Benke_current_and_future_risks.pdf

8 Roelofs C. Latency attention deficit: asbestos abatement workers need us to investigate. Am J Ind Med. 2015;58(12):1231-4.

9 Australian Institute of Health and Welfare. Australian cancer incidence and mortality (ACIM) books: mesothelioma. Canberra: Australian Institute of Health and Welfare; 2015 [cited 2016 Feb 25]. Available from: www.aihw.gov.au/WorkArea//DownloadAsset. aspx?id=60129554492
10 Australian Mesothelioma Registry (AMR). Mesothelioma in Australia 2014: 4th annual report. Sydney: Australian Mesothelioma Registry; 2015 [cited 2016 Feb 25]. Available from: www.mesothelioma-australia.com/ media/12174/amr_4thannualdatareport_final.pdf

11 Asbestos Response Taskforce. Long term management of loose fill asbestos insulation in Canberra homes. Canberra: ACT Government; 2014 [cited 2016 Feb 25]. Available from: www.asbestostaskforce.act.gov. au/_data/assets/pdf_file/0009/675189/Longtermmanagement-review.pdf

12 Hyland R, Yates D, Benke G, Sim M, Johnson AR. Occupational exposure to asbestos in New South Wales, Australia (1970-1989): development of an asbestos task exposure matrix. Occup Environ Med. 2010;67(3):201-6.

13 Bourdès V, Boffetta $P$, Pisani P. Environmental exposure to asbestos and risk of pleural mesothelioma: review and meta-analysis. Eur J Epidemiol. 2000;16(5):411-17.

14 Rake C, Gilham C, Hatch J, Darnton A, Hodgson J, Peto J. Occupational, domestic and environmental mesothelioma risks in the British population: a casecontrol study. Br J Cancer. 2009:100(7):1175-83.

15 Health Effects Institute - Asbestos Research. Asbestos in public and commercial buildings: a literature review and synthesis of current knowledge. Cambridge, MA: Health Effects Institute; 1991 [cited 2016 Feb 25]. Available from: pubs.healtheffects.org/getfile.php?u=699

16 The NORDCAN Project. NORDCAN cancer fact sheets: Denmark - pleura. 2015, NORDCAN. Copenhagen: Association of the Nordic Cancer Registries; 2015 [cited 2016 Feb 25]. Available from: www-dep.iarc.fr/NORDCAN/english/StatsFact. asp?cancer $=190 \&$ country $=208$

17 Sterling T, Collett C, Rosenbaum W, Weinkam JJ. Comments on the Health Effects Institute-Asbestos Research (HEI-AR) report: "Asbestos in public and commercial buildings," with emphasis on risk assessment methods used. Am J Ind Med. 1993;24(6):767-81.

18 Australian Institute of Health and Welfare. Cancer in Australia: an overview 2014. Canberra: Australian Institute of Health and Welfare; 2014 [cited 2016 Feb 25]. Available from: www.aihw.gov.au/WorkArea/ DownloadAsset.aspx?id=60129550202.

19 Western Australian Advisory Committee on Hazardous Substances. Asbestos cement products - report. Perth: Western Australian Advisory Committee on Hazardous Substances; 1991.

\section{Copyright: (c)}

(C) 2016 Armstrong \& Driscoll. This article is licensed under the Creative Commons Attribution-NonCommercial-ShareAlike 4.0 International Licence, which allows others to redistribute, adapt and share this work non-commercially provided they attribute the work and any adapted version of it is distributed under the same Creative Commons licence terms. See: www.creativecommons.org/licenses/by-nc-sa/4.0/ 